\title{
Effect of Benzoic Acid on Metabolic Fluxes in Yeasts: A Continuous-Culture Study on the Regulation of Respiration and Alcoholic Fermentation
}

\author{
CORNELIS VERDUYN*, ERIK POSTMA, W. ALEXANDER SCHEFFERS AND \\ JOHANNES P. VAN DIJKEN
}

Department of Microbiology and Enzymology, Kluyver Laboratory of Biotechnology, Delft University of Technology, Julianalaan 67, 2628 BC Delft, The Netherlands

Received 16 August 1991; accepted 3 February 1992

Addition of benzoate to the medium reservoir of glucose-limited chemostat cultures of Saccharomyces cerevisiae CBS 8066 growing at a dilution rate $(D)$ of $0.10 \mathrm{~h}^{-1}$ resulted in a decrease in the biomass yield, and an increase in the specific oxygen uptake rate $\left(\mathrm{qO}_{2}\right)$ from $2 \cdot 5$ to as high as $19.5 \mathrm{mmol} \mathrm{g}^{-1} \mathrm{~h}^{-1}$. Above a critical concentration, the presence of benzoate led to alcoholic fermentation and a reduction in $\mathrm{qO}_{2}$ to $13 \mathrm{mmol} \mathrm{g}^{-1} \mathrm{~h}^{-1}$. The stimulatory effect of benzoate on respiration was dependent on the dilution rate: at high dilution rates respiration was not enhanced by benzoate. Cells could only gradually adapt to growth in the presence of benzoate: a pulse of benzoate given directly to the culture resulted in wash-out.

As the presence of benzoate in cultures growing at low dilution rates resulted in large changes in the catabolic glucose flux, it was of interest to study the effect of benzoate on the residual glucose concentration in the fermenter as well as on the level of some selected enzymes. At $D=0 \cdot 10 \mathrm{~h}^{-1}$, the residual glucose concentration increased proportionally with increasing benzoate concentration. This suggests that modulation of the glucose flux mainly occurs via a change in the extracellular glucose concentration rather than by synthesis of an additional amount of carriers. Also various intracellular enzyme levels were not positively correlated with the rate of respiration. A notable exception was citrate synthase: its level increased with increasing respiration rate.

Growth of $S$. cerevisiae in ethanol-limited cultures in the presence of benzoate also led to very high qO $\mathrm{O}_{2}$ levels of 19-21 mmol $\mathrm{g}^{-1} \mathrm{~h}^{-1}$. During growth on glucose as well as on ethanol, the presence of benzoate coincided with an increase in the mitochondrial volume up to one quarter of the total cellular volume.

Also with the Crabtree-negative yeasts Candida utilis, Kluyveromyces marxianus and Hansenula polymorpha, growth in the presence of benzoate resulted in an increase in $\mathrm{qO}_{2}$ and, at high concentrations of benzoate, in aerobic fermentation. In contrast to $S$. cerevisiae, the highest $\mathrm{qO}_{2}$ of these yeasts when growing at $D=0 \cdot 10 \mathrm{~h}^{-1}$ in the presence of benzoate was equal to, or lower than the $\mathrm{qO}_{2}$ attainable at $\mu_{\max }$ without benzoate. Enzyme activities that were repressed by glucose in $S$. cerevisiae also declined in $K$. marxianus when the glucose flux was increased by the presence of benzoate.

The maximal aerobic fermentation rate at $D=0 \cdot 10 \mathrm{~h}^{-1}$ of the Crabtree-negative yeasts at high benzoate concentrations was considerably lower than for $S$. cerevisiae. This is probably due to the fact that under aerobic conditions these yeasts are unable to raise the low basal pyruvate decarboxylase level: cultivation without benzoate under oxygenlimited conditions resulted in rates of alcoholic fermentation and levels of pyruvate decarboxylase comparable to those of $S$. cerevisiae.

KEY WORDS - Benzoic acid: yeasts; Crabtree effect; respiration; fermentation; mitochondria; metabolic flux.

\section{INTRODUCTION}

In yeasts, glucose catabolism can occur via respiration, via alcoholic fermentation, or by a combination of these two pathways. Which pathway prevails depends on a number of factors, including strain and culture conditions. For instance,

*Addressee for correspondence.

0749-503X/92/070501-17\$13.50

(c) 1992 by John Wiley \& Sons Ltd
Saccharomyces cerevisiae cultivated in aerobic glucose-limited chemostat cultures shows respirative growth at low dilution rates. Fermentation, together with respiration at an approximately constant specific rate occurs at high growth rates (Barford and Hall, 1979; Rieger et al., 1983). The occurrence of alcoholic fermentation under aerobic conditions is known as the Crabtree effect. The 
Crabtree effect may occur under steady-state conditions (long-term effect, Fiechter et al., 1981) or may be triggered during transient state (short-term effect, Petrik et al., 1983; van Urk et al., 1988): when glucose-limited cultures of $S$. cerevisiae are suddenly exposed to excess glucose, alcoholic fermentation is observed (Woehrer and Roehr, 1981; Verduyn et al., 1984). However, the majority of yeasts, for example representatives of the genera Candida, Hansenula, Kluyveromyces and Rhodotorula, are Crabtreenegative; they do not perform aerobic alcoholic fermentation in the presence of high sugar concentrations, irrespective whether chemostat or batch cultivation is employed.

It is generally assumed that the major difference between $S$. cerevisiae and Crabtree-negative yeasts such as Candida utilis is the respiratory capacity (mmol $\mathrm{O}_{2}$ consumed $\mathrm{g}^{-1} \mathrm{~h}^{-1}$ ). Crabtree-negative species can attain considerably higher respiration rates than $S$. cerevisiae (Alexander and Jeffries, 1990; Barford, 1990). However, it has been shown recently that addition of butyrate to glucoselimited cultures of $S$. cerevisiae growing at a low dilution rate increased the in situ $\mathrm{qO}_{2}$ from 2.5 to approximately $16 \mathrm{mmol} \mathrm{g}^{-1} \mathrm{~h}^{-1}$ (Verduyn et al., 1992). This was considerably higher than the $\mathrm{qO}_{2}$ observed with glucose-limited cultures growing without butyrate at a rate approaching $\mu_{\max }$. This increase in $\mathrm{qO}_{2}$ in the presence of butyrate was accompanied by a decrease in the biomass yield, as a larger part of the glucose was dissimilated. This observation prompted us to study the effects of weak acids on respiration in more detail. Benzoate, rather than butyrate, was chosen as a model acid, since benzoic acid was not metabolized by the yeasts used in this study. This is in contrast to butyrate, for example, which could serve as a carbon source for $C$. utilis (Verduyn et al., unpublished).

The experiments described in this paper were aimed at answering the following questions:

(1) Is the maximal respiratory capacity of Crabtreepositive yeasts like $S$. cerevisiae intrinsically lower than that of Crabtree-negative yeasts?

(2) Can aerobic alcoholic fermentation (i.e. a Crabtree effect) also be provoked in Crabtreenegative yeasts?

(3) Can changes in metabolic fluxes that are observed during growth of yeasts in the presence of weak acids be explained in terms of enzyme levels, particularly with respect to key enzymes of respiratory pathways?

\section{METHODS}

\section{Microrganisms and growth conditions}

Saccharomyces cerevisiae CBS 8066, Candida utilis CBS 621, Hansenula polymorpha ATCC 46059 and Kluyveromyces marxianus CBS 6556 were grown in carbon-limited chemostat cultures at $\mathbf{p H}$ 5.0 and $30^{\circ} \mathrm{C}$ (except $K$. marxianus, which was grown at $37^{\circ} \mathrm{C}$ ) in a fermenter as described by Harder et al. (1974), on a mineral medium containing per litre: $\left(\mathrm{NH}_{4}\right)_{2} \mathrm{SO}_{4}, 5 \mathrm{~g} \quad \mathrm{KH}_{2} \mathrm{PO}_{4}, 3 \mathrm{~g}$; $\mathrm{MgSO}_{4} .7 \mathrm{H}_{2} \mathrm{O}, 0.5 \mathrm{~g}$; EDTA, $15 \mathrm{mg} ; \mathrm{ZnSO}_{4} .7 \mathrm{H}_{2} \mathrm{O}$, $4.5 \mathrm{mg} ; \mathrm{CoCl}_{2} .6 \mathrm{H}_{2} \mathrm{O}, 0.3 \mathrm{mg} ; \mathrm{MnCl}_{2} \cdot 4 \mathrm{H}_{2} \mathrm{O}, 1 \mathrm{mg}$; $\mathrm{CuSO}_{4} .5 \mathrm{H}_{2} \mathrm{O}, \quad 0.3 \mathrm{mg} ; \quad \mathrm{CaCl}_{2} \cdot 2 \mathrm{H}_{2} \mathrm{O}, \quad 4.5 \mathrm{mg}$; $\mathrm{FeSO}_{4} .7 \mathrm{H}_{2} \mathrm{O}, 3 \mathrm{mg} ; \quad \mathrm{NaMoO}_{4} .2 \mathrm{H}_{2} \mathrm{O}, \quad 0.4 \mathrm{mg}$; $\mathrm{H}_{3} \mathrm{BO}_{3}, 1 \mathrm{mg}-\mathrm{KI}, 0.1 \mathrm{mg}$; and $0.025 \mathrm{ml}$ silicone antifoam (BDH). Filter-sterilized vitamins were added after heat sterilization $\left(120^{\circ} \mathrm{C}\right)$ of this medium. Final vitamin concentrations per litre were: biotin, $0.05 \mathrm{mg}$; calcium pantothenate, $1 \mathrm{mg}$; nicotinic acid, $1 \mathrm{mg}$; inositol, $25 \mathrm{mg}$; thiamine $\mathrm{HCl}, 1 \mathrm{mg}$; pyridoxine $\mathrm{HCl}, 1 \mathrm{mg}$; and para-aminobenzoic acid, $0.2 \mathrm{mg}$.

Stirrer rate was $800 \mathrm{rpm}$, with an air flow rate of $21 \mathrm{~min}^{-1}$, to give a dissolved-oxygen tension of at least $50 \%$ of air saturation under all experimental conditions. The condensor of the fermenter was connected to a cryostat and cooled at $2^{\circ} \mathrm{C}$. The carbon source consisted of $10 \mathrm{gl}^{-1}$ glucose or $7.5 \mathrm{~g} \mathrm{l}^{-1}$ ethanol. When ethanol served as the carbon source, the medium reservoir was placed in a refrigerator. Sodium benzoate, sterilized as a $20 \%$ solution at $110^{\circ} \mathrm{C}$ for $15 \mathrm{~min}$, was added to the medium reservoir.

For oxygen-limited conditions, the air supply was replaced by nitrogen gas (Air Products, The Netherlands) with a flow rate of $11 \mathrm{~min}^{-1}$ via a flow controller. No special precautions were taken to prevent diffusion of oxygen into the system. The tubing consisted of silicone and the medium reservoir was not flushed with nitrogen.

\section{Enzyme assays}

Spectrophotometric assays were carried out at $30^{\circ} \mathrm{C}$ with freshly-prepared extracts as described by . Postma et al. (1989a). Reaction rates were linearly proportional to the amount of enzyme added. Preparation of cell-free extracts, and assays of pyruvate decarboxylase (PDC; EC 4.1.1.1), alcohol dehydrogenases (ADH; EC 1.1.1.1, with either $100 \mathrm{~mm}$-ethanol or $25 \mathrm{~mm}$-pentanol as substrate), acetaldehyde dehydrogenases (EC 1.2.1.4 
and 1.2.1.5) and acetyl-CoA synthetase (EC 6.2.1.1) were performed as described by Postma et al. (1989a). NADH dehydrogenase (EC 1.6.99.3) and cytochrome $c$ oxidase (EC 1.9.3.1) were assayed according to Bruinenberg et al. (1985), citrate synthase (EC 4.1.3.7) according to Srere (1969) and hexokinase (EC 2.7.1.1) according to Postma et al. (1988). One unit is defined as the amount of enzyme catalyzing the conversion of $1 \mu \mathrm{mol}$ substrate $\min ^{-1}$. Specific activity is expressed as units $\mathrm{mg}$ protein $^{-1}$. Catalase units are expressed as $\Delta A_{240}$ $\min ^{-1}$.

Protein concentrations of cell-free extracts were determined according to the Lowry method with bovine serum albumin (Sigma, fatty-acid free) as a standard.

\section{Analytical methods}

Dry weight of cultures was determined via filtration as described by Postma et al. (1989a). This parameter was regularly checked, both in the culture samples and in the effluent, to establish whether representative sampling of biomass from the fermenter occurred. The biomass concentration in the outlet was always within $3 \%$ of that in the fermenter.

Pyruvate and acetate in culture supernatants were analyzed by HPLC as described previously (Verduyn et al., 1990a). Glycerol was analyzed by the same method. Glucose in medium reservoirs was assayed with the Boehringer GOD-PAP glucose kit (no. 676543) or with HPLC on the system described above. Residual glucose concentrations in the fermenter were assayed with the Boehringer glucose/ hexokinase kit (no. 716251) after fast sampling of culture fluid in liquid nitrogen as described by Postma et al. (1988). Ethanol was assayed colorimetrically as described by Verduyn et al. (1990a) or with HPLC. Benzoate can also be assayed with this HPLC set-up; however, it eluted late (retention time approximately $40 \mathrm{~min}$ ), which resulted in broad peaks. Concentrations below $1.5 \mathrm{~mm}$ could not be determined accurately. Between 1.5 and $2.5 \mathrm{~mm}$, the accuracy was $10-20 \%$ (depending on the concentration) and it increased to better than $10 \%$ at benzoate concentrations higher than $2.5 \mathrm{~mm}$.

\section{Gas analysis}

Analysis of oxygen consumption and carbon dioxide production in chemostat cultures was performed according to Postma et al. (1989a). Cultures were checked for the occurrence of oscillations (Parelukar et al., 1986; Sonnleitner, 1991). When oscillations occurred, the experiments were postponed till the oscillations had dampened out. If this did not occur within 10 volume changes, cultivation was terminated and restarted with a clean fermenter.

\section{Polarographic measurements}

In order to establish the instantaneous maximum respiratory capacity $\left(\mathrm{qO}_{2}{ }^{\max }\right)$ of a culture in the presence of excess substrate, 5-ml samples were taken from the fermenter, washed once at room temperature with $10 \mathrm{ml}$ complete medium without the carbon source, and resuspended to $5 \mathrm{ml}$ with medium not containing the carbon source. This suspension was continuously stirred and aerated to prevent oxygen-limited conditions. A $100 \mu \mathrm{l}$ sample was then added to a stirred vessel (Biological Oxygen Monitor, Yellow Springs, USA) containing $4.8 \mathrm{ml}$ air-saturated medium $\left(\mathrm{pH} 5 \cdot 0,30^{\circ} \mathrm{C}\right)$. Endogenous respiration was followed for $5 \mathrm{~min}$ with a Clark-type oxygen electrode. The instantaneous respiratory capacity was then determined following the addition of $100 \mu$ glucose or ethanol to a final concentration of $20 \mathrm{~mm}$, assuming a dissolved-oxygen concentration of $0.235 \mu \mathrm{mol} \mathrm{ml}^{-1}$ at $30^{\circ} \mathrm{C}$.

\section{ATP assays}

For the determination of ATP in biomass, a fresh cell sample was immediately diluted 100 -fold in $0.9 \% \mathrm{NaCl}$ and processed with a Lumac 3M Biocounter according to the instructions of the manufacturer. Benzoate did not interfere with this assay.

\section{Electron microscopy}

For electron micrographs, cells were fixed and stained as described in Visser et al. (1990). The mitochondrial volume was calculated from the micrographs according to the method of Weibel and Bolender (1973).

\section{Chemicals}

Sodium benzoate was obtained from Baker.

\section{RESULTS}

Effect of benzoate on glucose-limited cultures of

S. cerevisiae at $\mathrm{D}=0 \cdot 10 \mathrm{~h}^{-1}$

Weak acids such as benzoate may 'uncouple' energy generation from biomass formation by dissipating the proton-motive force across the plasma 


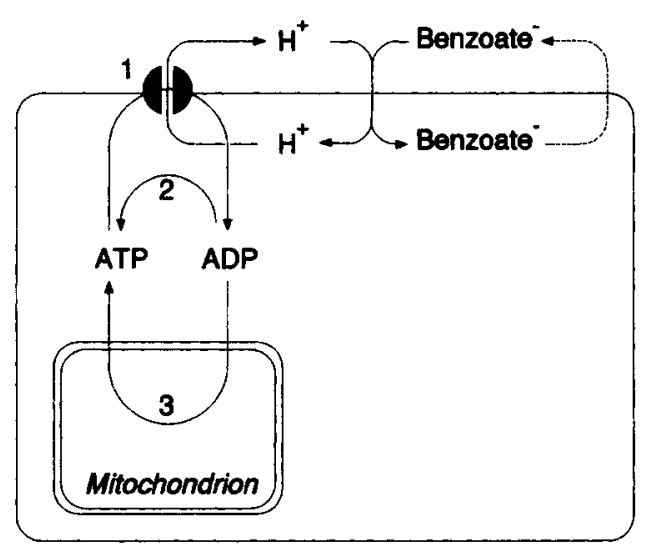

Figure 1. Schematic representation of uncoupling by benzoic acid at the level of the plasma membrane. 1: Plasma membrane ATPase; 2: ATP generation via substrate-level phosphorylation, and 3: ATP generation via respiration.

membrane, due to influx of the undissociated acid. The resultant drop in cytosolic $\mathrm{pH}$ can be neutralized by the action of plasma membrane ATPase, which hydrolyzes ATP and pumps protons out of the cell. Thus, additional ATP has to be generated to compensate the influx of acid. This may be achieved via an increased respiration rate, as schematically shown in Figure 1.

Addition of benzoate to the medium reservoir of glucose-limited cultures of $S$. cerevisiae CBS 8066 growing at a dilution rate $(D)$ of $0 \cdot 10 \mathrm{~h}^{-1}$ resulted in a concentration-dependent decrease of the biomass yield from $0.51 \mathrm{~g}$ biomass $\mathrm{g}$ glucose ${ }^{-1}$ without benzoate, to $0 \cdot 15 \mathrm{~g} \mathrm{~g}^{-1}$ at a residual concentration of $10 \mathrm{~mm}$-benzoate (Figure 2 ). The specific oxygen consumption rate $\left(\mathrm{qO}_{2}\right)$ increased from $2 \cdot 5 \pm 0 \cdot 2$ in the absence of benzoate, to a value as high as $19.5 \pm 1 \mathrm{mmol} \mathrm{g}^{-1} \mathrm{~h}^{-1}$ at a residual benzoate concentration of $10 \mathrm{~mm}$ (Figure 2). The highest measured value of the specific oxygen uptake rate in the presence of benzoate will be indicated as the 'critical respiratory capacity' (Table 1 ). Up to the corresponding benzoate concentration $(10 \mathrm{~mm})$, biomass and $\mathrm{CO}_{2}$ were the only main products. The respiratory quotient (RQ) was between 0.95 and $1 \cdot 10$ for all steady states. When the benzoate concentration was increased further to $10.5 \mathrm{mM}$, a large drop in cell yield occurred and ethanol formation became apparent. The yield declined to $0.09 \mathrm{~g}$ biomass g glucose $e^{-1}$, with an ethanol production rate of $6.4 \mathrm{mmol} \mathrm{g} \mathrm{g}^{-1} \mathrm{~h}^{-1}$. However, a normal steady state could be established. The $\mathrm{qO}_{2}$ decreased to a constant value of $13 \pm 1 \mathrm{mmol} \mathrm{g}^{-1} \mathrm{~h}^{-1}$ (Figure 2).

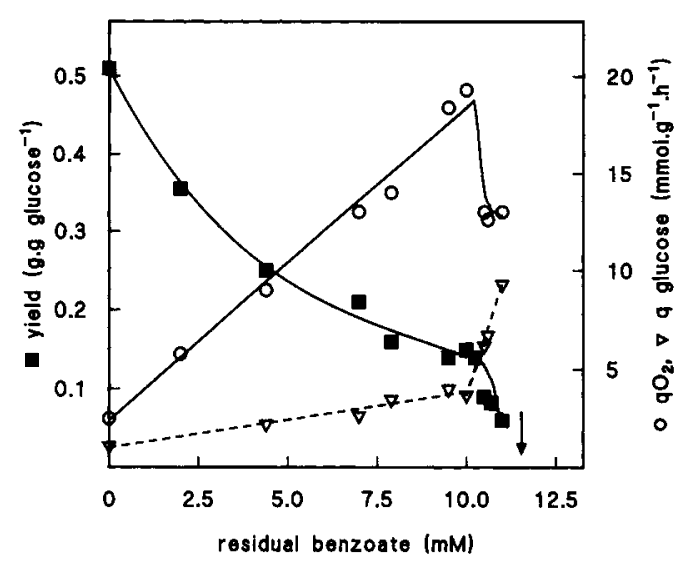

Figure 2. Biomass yield ( $\boldsymbol{\square})$, specific oxygen consumption rate $(O)$ and glucose flux $(\Delta)$ as a function of the residual benzoate concentration during glucose-limited growth of $S$. cerevisiae CBS 8066 . The dilution rate was $0 \cdot 10 \mathrm{~h}^{-1}$. The arrow indicates the benzoate concentration at which the culture washed out.

Table 1. Definition of various specific oxygen uptake rates

\begin{tabular}{ll} 
Term & \multicolumn{1}{c}{ Definition } \\
\hline $\mathrm{qO}_{2}$ & $\begin{array}{c}\text { Specific oxygen uptake rate, measured in situ } \\
\text { via analysis of the exhaust gas of cultures } \\
\mathrm{qO}_{2} \text { of washed cell samples (i.e. not } \\
\text { containing benzoate) upon addition of } \\
\text { excess substrate. } \mathrm{qO}_{2}^{\text {max }} \text { values were } \\
\text { assessed by oxygen probe measurements } \\
\text { Highest } \mathrm{qO}_{2} \text { measured in situ in the presence } \\
\text { of benzoate. The value of } \mathrm{qO}_{2}^{\text {crit }} \text { was } \\
\text { assessed by analysis of the culture exhaust } \\
\text { gas via gradual increase of the benzoate } \\
\text { concentration in the medium reservoir }\end{array}$ \\
$\mathrm{qO}_{2}^{\text {crit }}$ &
\end{tabular}

A further increase in the benzoate concentration resulted in increased fermentation, and a further decrease in the biomass yield to $0.06 \mathrm{~g}$ biomass $\mathrm{g}$ glucose $e^{-1}$, but the cells maintained the same $\mathrm{qO}_{2}$. Cultures were run for another $150 \mathrm{~h}$ but no changes in dry weight, $\mathrm{qO}_{2}$ or q ethanol were observed.

The above phenomena were independent of the reservoir glucose concentration: the same fluxes were obtained when the glucose concentration in the medium-reservoir was doubled.

The presence of benzoate resulted in an increase in the pyruvate concentration in the culture from $0.07 \mathrm{~mm}$, without benzoate, to $0.17 \mathrm{mM}$ at $10 \mathrm{~mm}$ 
residual benzoate. Acetate was also encountered, its concentration increased from $1.1 \mathrm{mM}$ to $1.7 \mathrm{~mm}$ between benzoate concentrations of 0 and $10 \mathrm{~mm}$. Although these are comparatively small increases, it can be calculated that the specific production rates of pyruvate and acetate increased seven-fold and five-fold, respectively, in the presence of $10 \mathrm{~mm}$ residual benzoate, as compared to cultures without benzoate.

In all steady-state situations $90 \pm 5 \%$ of the benzoate added to the medium reservoir was recovered in the medium. If it is assumed, for simplicity, that all intracellular benzoate is present in the cytosol, it can be calculated, with a cytosolic volume of $2.0 \mathrm{ml} \mathrm{g} \mathrm{cells}^{-1}$ (Valle et al., 1986; Warth, 1988), that the total intracellular concentration (anion and acid) would be $0.37 \mathrm{M}$ at a residual benzoate concentration in the culture fluid of $10 \mathrm{~mm}$; in other words, an accumulation factor of 37. Although this concentration factor is considerable, it is still significantly lower than expected if the weak acid is distributed according to the $\Delta \mathrm{pH}$. In that case, it can be calculated that benzoate ( $\mathrm{p} K=4 \cdot 19)$ should accumulate $357 \times$, assuming an intracellular $\mathrm{pH}$ of approximately $7 \cdot 0$ (cf Verduyn et al., 1990a for calculations and references). Also from the experimental data of Warth (1988) for a number of yeasts, an accumulation factor for benzoate of only 15-20 $\times$ can be calculated.

\section{Effect of a benzoate pulse on $\mathrm{S}$. cerevisiae}

In order to establish if, and to what extent, an instantaneous increase in $\mathrm{qO}_{2}$ occurs upon addition of a non-metabolizable weak acid, a pulse of benzoate was given directly to a glucose-limited culture, pregrown without benzoate.

Injection of $10 \mathrm{~mm}$-benzoate to a glucose-limited chemostat culture $\left(D=0 \cdot 11 \mathrm{~h}^{-1}\right)$ of $S$. cerevisiae CBS 8066, with the medium supply left running to provide a carbon and energy source, resulted in an immediate decrease in dry weight, and accumulation of glucose (Figure 3A). The intracellular ATP concentration increased from the steady-state value of $2.2 \mathrm{~mm}$ to approximately $4 \mathrm{~mm}$ and subsequently declined to $1 \mathrm{~mm}$ (Figure 3A). During the initial period after the pulse, acetate accumulated up to $25 \mathrm{~mm}$. The pyruvate concentration in the culture increased six-fold. Remarkably, however, alcoholic fermentation remained very low during the first $10 \mathrm{~h}$ after the pulse. The in-situ specific oxygen uptake rate declined from $2.5 \mathrm{mmol} \mathrm{O}_{2} \mathrm{~g}^{-1} \mathrm{~h}^{-1}$ to approximately $1 \mathrm{mmol} \mathrm{g}^{-1} \mathrm{~h}^{-1}$. Nevertheless, measurement
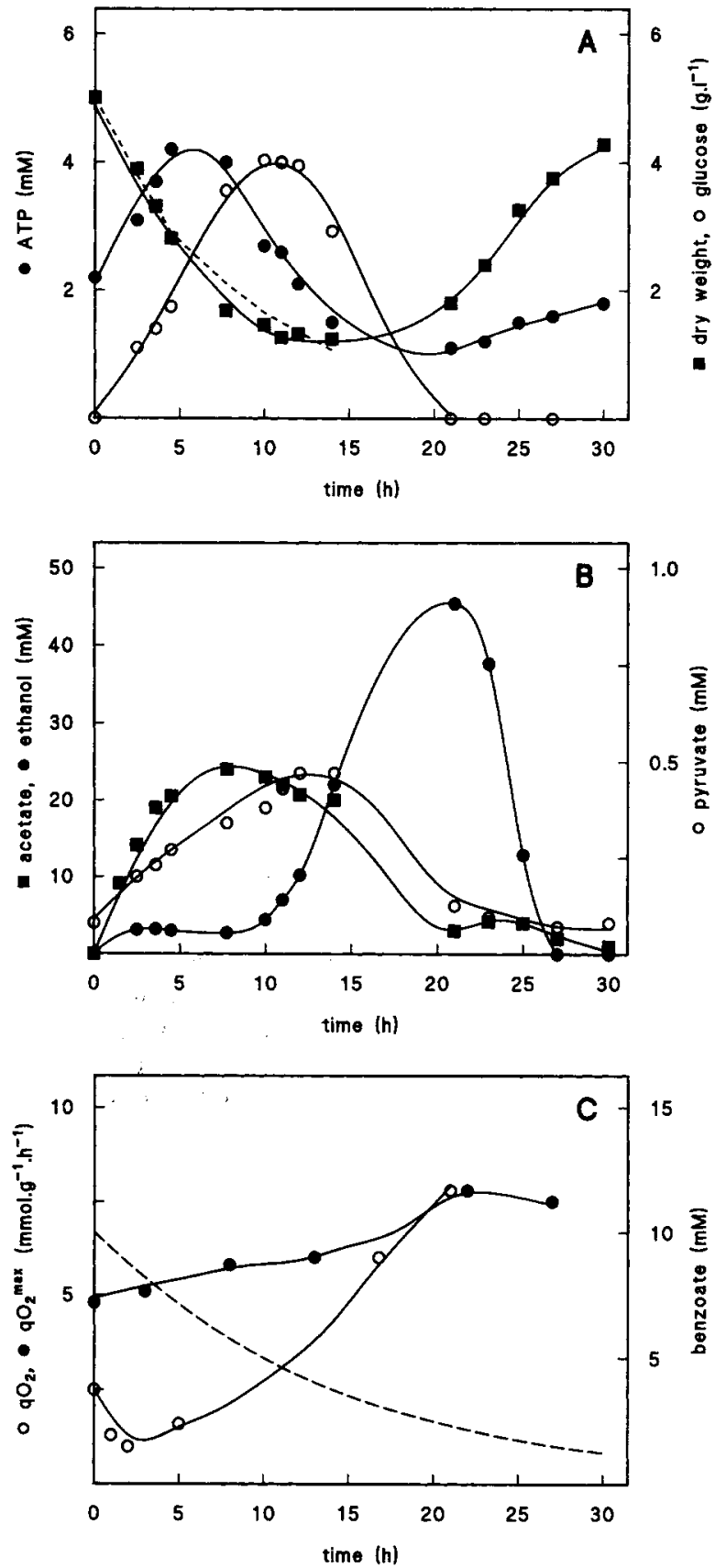

Figure 3. (A) Dry weight ( $\boldsymbol{D})$, glucose concentration $(O)$ and intracellular ATP concentration ( () during a benzoate pulse (10 mM) to a glucose-limited chemostat culture $\left(S_{\mathrm{r}}=10 \mathrm{gl}^{-1}\right)$ of $S$. cerevisiae CBS 8066 at $D=0 \cdot 11 \mathrm{~h}^{-1}$. The broken line shows the theoretical wash-out curve of biomass, assuming no growth. (B) Concentrations of acetate $(\square)$, ethanol $(O)$ and pyruvate $(O)$. Conditions as in (A). (C) In-situ specific oxygen consumption rate (O) and instantaneous maximum $\mathrm{qO}_{2}$ of washed cells $(\bullet)$. Conditions as in (A). 
of the oxygen consumption rate of cell samples after removal from the fermenter and washing indicated that the cells had retained a normal instantaneous $\mathrm{qO}_{2}{ }^{\max }$ (for definitions see Table 1) of approximately $5 \mathrm{mmol} \mathrm{g}^{-1} \mathrm{~h}^{-1}$ (Figure 3B). After several hours, a rapid increase in ethanol production was observed, with a concomitant decline in residual glucose concentration. In the second phase, rapid uptake of ethanol occurred, accompanied by an increase in biomass concentration and a gradual return of the intracellular ATP concentration to the normal steady-state value (Figure 3A). This phase was associated with increased in-situ $\mathrm{qO}_{2}$ as well as increased $\mathrm{qO}_{2}{ }^{\text {max }}$ values (Figure $3 \mathrm{C}$ ). It can be concluded from these experiments that cells have to adapt gradually to benzoate: the phenomena observed upon a pulse of benzoate are different as compared to a gradual increase in the benzoate concentration in the medium reservoir (Figure 2). Sudden exposure to a high concentration of benzoate results in inhibition, rather than stimulation of respiration.

\section{Effect of growth rate on benzoate-mediated modulation of metabolic fluxes in glucose-limited S. cerevisiae cultures}

Analogous to the experiments described above, the effect of benzoate additions to the medium reservoir was studied at other dilution rates in order to determine the critical respiratory capacity at a given dilution rate. This critical respiratory capacity is defined as the highest oxygen uptake rate measured in-situ in the presence of benzoate (Table 1). The critical respiratory capacity appeared to be maximal between $D=0 \cdot 10$ and $0 \cdot 20 \mathrm{~h}^{-1}$ (Figure 4). Between dilution rates of $0.20 \mathrm{~h}^{-1}$ and $0.38 \mathrm{~h}^{-1}$, the highest attainable dilution rate without alcoholic fermentation in cultures without benzoate (Postma et al., 1989a), the critical respiratory capacity $\mathrm{qO}_{2}$ decreased from $20 \pm 1 \cdot 5$ to $12 \pm 1 \mathrm{mmol} \mathrm{g}^{-1} \mathrm{~h}^{-1}$ (Figure 4). Addition of benzoate to cultures growing at $D>0.38 \mathrm{~h}^{-1}$ did not result in an increase in $\mathrm{qO}_{2}$ but only in a decrease in yield and an increase in ethanol production (results not shown).

The amount of benzoate which had to be added with increasing dilution rate to achieve a given amount of reduction of the biomass yield, or a given increase in $\mathrm{qO}_{2}$ as compared to growth without benzoate, increased with growth rate. For instance, the residual benzoate concentrations required for a $50 \%$ reduction of the biomass yield at dilution rates of 0.1 and $0.2 \mathrm{~h}^{-1}$ (yield $0.51 \mathrm{gg}$ glucose $\mathrm{g}^{-1}$ in the

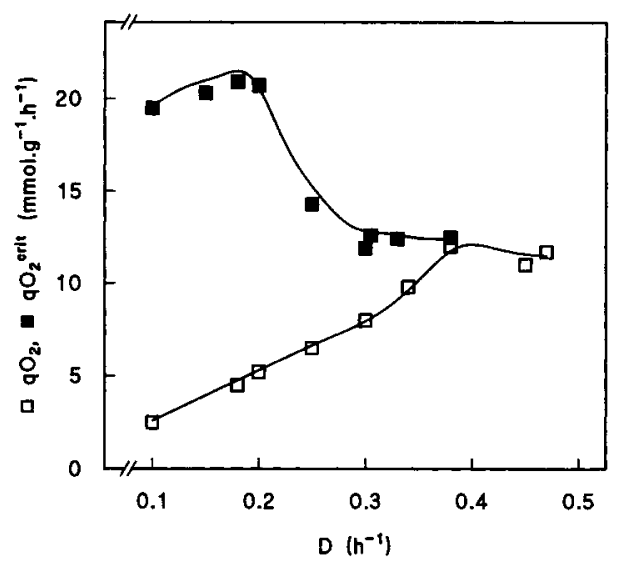

Figure 4. Critical specific oxygen consumption rate (a) in the presence of benzoate and $\mathrm{qO}_{2}$ in the absence of benzoate $(\square)$ as a function of the dilution rate during glucose-limited growth of S. cerevisiae CBS 8066.

absence of benzoate) were approximately $4.3 \mathrm{~mm}$ (Figure 2) and $9 \mathrm{~mm}$, respectively (not shown). However, the total amount of benzoate which can be tolerated by the culture quickly declines at $D>0.2 \mathrm{~h}^{-1}$. This is due to the fact that the difference between the critical respiratory capacity and the insitu $\mathrm{qO}_{2}$ becomes smaller with increasing growth rate (Figure 4). These results suggest that the effect of benzoate probably is a typical growth rateindependent maintenance energy effect (Pirt, 1965), as shown previously for propionate with anaerobic glucose-limited cultures of S. cerevisiae CBS 8066 (Verduyn et al., 1990b).

\section{Regulation of glucose transport in S. cerevisiae}

Since addition of benzoate to the medium feed of glucose-limited chemostat cultures led to a large increase in glucose flux (Figure 2), it was of interest to study the residual glucose concentration(s) in the fermenter. During aerobic glucose-limited growth at $D=0 \cdot 10 \mathrm{~h}^{-1}$, two glucose transport systems are present, with $K_{\mathrm{m}}$ values of 1 and $20 \mathrm{mM}$, and $V_{\max }$ values of approximately 160 and $120 \mu \mathrm{mol} g$ biomass $^{-1} \mathrm{~min}^{-1}$, respectively (Postma et al., 1989b). The in-situ glucose flux $\left(q_{\text {glucose }}\right)$ depends on the residual substrate concentration in the fermenter and the kinetic properties of the glucose transporters, i.e $K_{\mathrm{m}}$ and $V_{\max }$, according to: $q=\sum\left(V_{\max }{ }^{*} s\right) /$ $\left(K_{\mathrm{m}}+s\right)$. In order to estimate the in-situ transport activity at a fixed dilution rate of $0 \cdot 10 \mathrm{~h}^{-1}$, but at different glucose fluxes, the residual glucose concentration in the fermenter was determined in steady 


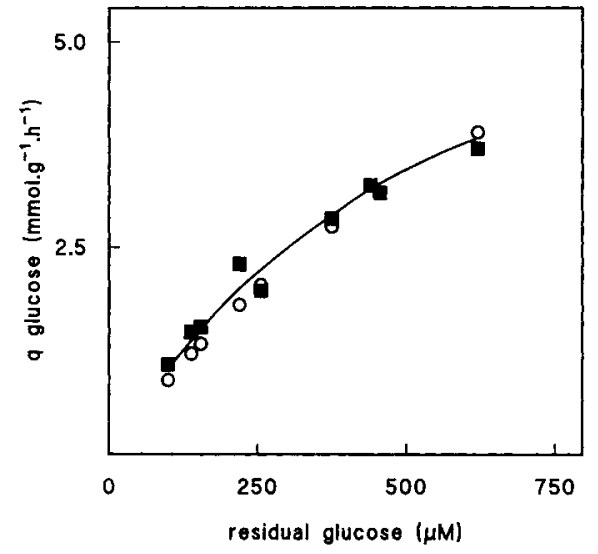

Figure 5. In-situ glucose flux (q glucose) as a function of the residual glucose concentration in the fermenter (after fast sampling) during glucose-limited growth of $S$, cerevisiae CBS 8066 in the presence of increasing amounts of benzoate ( $\square$ ) and q glucose calculated from the kinetic parameters of glucose carriers in $S$. cerevisiae (see text) (O). The dilution rate was $0 \cdot 10 \mathrm{~h}^{-1}$.

states at different residual benzoate concentrations. The residual glucose concentration in the fermenter increased with increasing amounts of benzoate from $100 \mu \mathrm{M}$ without benzoate to $600 \mu \mathrm{M}$ at a residual benzoate concentration of $10 \mathrm{~mm}$. This was associated with an increase in the glucose flux from $1 \cdot 1$ to $3.9 \mathrm{mmol} \mathrm{g}^{-1} \mathrm{~h}^{-1}$ (Figure 5), the highest flux observed without alcoholic fermentation (Figure 2). With the equation shown above, the transport activity, which is the sum of the activities of the two carriers involved, can be calculated. The data thus obtained show a good fit with the glucose flux as calculated from the equation shown above (Figure 5). For example, it can be calculated that with a residual glucose concentration of $600 \mu \mathrm{M}$, the activity of the glucose carriers results in a $q_{\text {glucose }}$ of $3.8 \mathrm{mmol} \mathrm{g}^{-1} \mathrm{~h}^{-1}$ (of which only $5 \%$ is due to the low-affinity carrier).

Enzyme levels in glucose-limited cultures of $\mathrm{S}$. cerevisiae at $\mathrm{D}=0 \cdot 10 \mathrm{~h}^{-1}$

To investigate whether the increase in glucose flux correlated with an adjustment of enzyme levels, several key enzymes in different parts of the central metabolism, i.e. glycolysis, tricarboxy acid (TCA) cycle and respiratory chain, were assayed. The specific activity of the various enzymes as a function of the glucose flux is shown in Figure 6A-C.
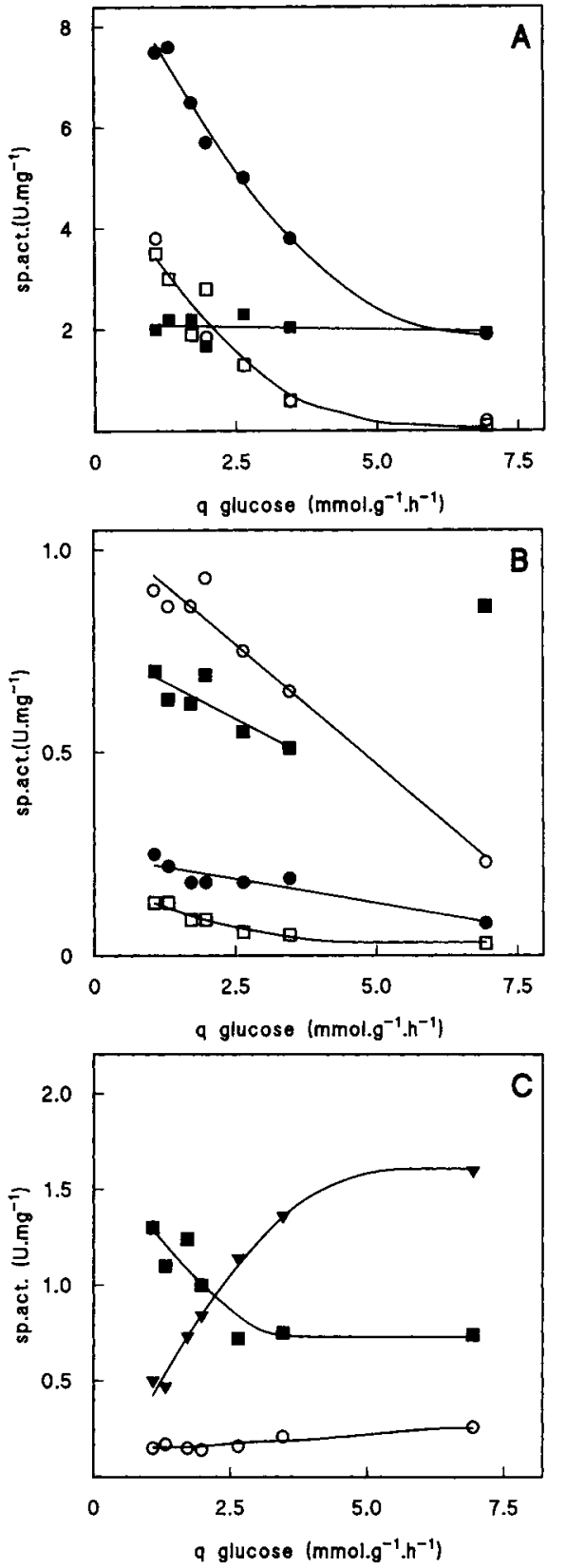

Figure 6. Specific activities ( $\mathrm{U}$ mg protein ${ }^{-1}$ ) of selected enzymes as a function of the glucose flux following addition of benzoate to glucose-limited $S$. cerevisiae CBS 8066. The first point represents the value without benzoate. The dilution rate was $0 \cdot 10 \mathrm{~h}^{-1}$. (A) Hexokinase ( $\mathrm{D}$ ), catalase ( $\square$ ), ethanoldependent alcohol dehydrogenase (O) and pentanol-dependent alcohol dehydrogenase $(0)$. Only a few assays of the latter have been made. (B) Pyruvate decarboxylase (G), NAD ${ }^{+}(0)$ and $\mathrm{NADP}^{+}(\mathbf{O})$-dependent acetaldehyde dehydrogenase, and acetyl-CoA synthetase ( $\square$ ). (C) NADH dehydrogenases ( $\square$ ), citrate synthase $(\nabla)$ and cytochrome $c$ oxidase $(O)$. 
Hexokinase activity was not significantly affected with increasing benzoate concentrations at $D=$ $0.10 \mathrm{~h}^{-1}$. Its activity was approximately $2 \mathrm{U}$ (mg protein $)^{-1}$, similar to that reported in glucose-limited chemostat cultures between $D=0.10$ and $0.39 \mathrm{~h}^{-1}$ for this strain (Postma et al., 1989a). Catalase activity declined drastically, almost 40 -fold, from 3.5 to $0.1 \mathrm{U} \mathrm{mg} \mathrm{protein}{ }^{-1}$ (Figure 6A).

Several isoenzymes of ADH occur in S. cerevisiae. Two of these enzymes, which are localized in the cytosol and in the mitochondria, respectively, are glucose-repressible. The cytosolic, repressible ADH which functions in the oxidation of ethanol, has a high activity towards pentanol (Bränden et al., 1975). This also holds for the mitochondrial ADH. The function of the latter enzyme is not known (Fraenkel, 1982). In addition to these repressible ADHs, a constitutive ADH is found in the cytosol. This enzyme, which functions in the formation of ethanol from acetaldehyde, has virtually no reactivity toward pentanol (Lutstorfand Magnet, 1968; Verduyn et al., 1988). The levels of both ethanol- and pentanoldependent ADH activity decreased strongly with the glucose flux (Figure 6B).

Of the enzymes of the pyruvate 'bypass' (PDC, acetaldehyde dehydrogenases and acetyl-CoA synthetase) (Holzer and Goedde, 1957), PDC was not significantly affected (Figure 6B). However, the other enzymes of the bypass, the $\mathrm{NAD}^{+}$- and $\mathrm{NADP}^{+}$-dependent acetaldehyde dehydrogenases and acetyl-CoA synthetase, decreased by a factor of three (Figure 6B) with increasing glucose fluxes. Citrate synthase activity increased in specific activity from 0.5 to $1.6 \mathrm{U} \mathrm{mg} \mathrm{protein}^{-1}$. A small decrease in NADH-dehydrogenase activity was observed, whereas cytochrome $c$ oxidase activity was almost constant (Figure 6C).

\section{Effect of benzoate on ethanol-limited cultures of S. cerevisiae}

It is often assumed that the inability of $S$. cerevisiae strains to respire sugars at a high rate resides at the level of pyruvate, i.e. is caused by a limitation in the rate of supply of pyruvate to the TCA cycle, or by a low oxidation rate of pyruvate (reviewed by Käppeli, 1986; Ratledge, 1991). It was therefore investigated to what extent benzoate affects respiration on a growth substrate that is not metabolized via pyruvate as a key intermediate.

Addition of benzoate to the medium reservoir of an ethanol-limited culture of $S$. cerevisiae growing

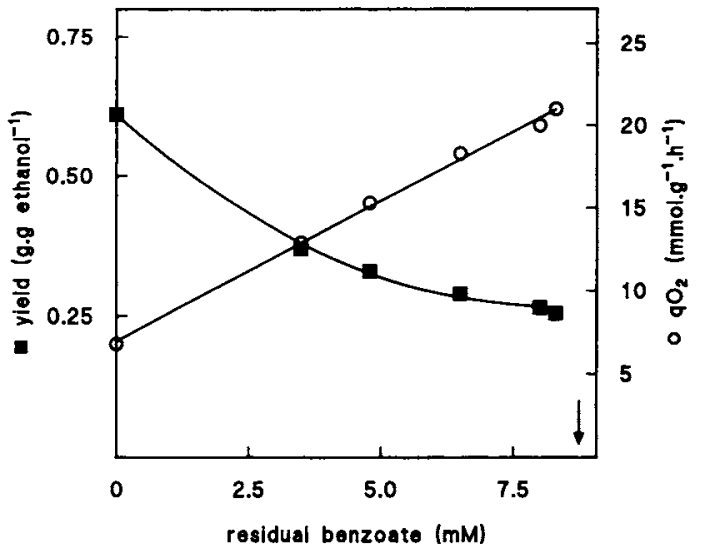

Figure 7. Biomass yield ( $\boldsymbol{E}$ ) and specific oxygen consumption rate $(O)$ as a function of the residual benzoate concentration during ethanol-limited growth of $S$. cerevisiae CBS 8066 . The dilution rate was $0 \cdot 10 \mathrm{~h}^{-1}$. The arrow indicates the benzoate concentration at which the culture washed out.

at $D=0 \cdot 10 \mathrm{~h}^{-1}$ also resulted in a decrease in the biomass yield and a linear increase in $\mathrm{qO}_{2}$ to a value of $21 \pm 1.5 \mathrm{mmol} \mathrm{g}^{-1} \mathrm{~h}^{-1}$ (Figure 7) at a residual benzoate concentration of $8 \mathrm{mM}$. A further addition of $1 \mathrm{~mm}$-benzoate to the reservoir resulted in accumulation of ethanol and acetate and wash-out. Ethanol-limited chemostat cultures without benzoate exhibited a yield of $0.61 \pm 0.02 \mathrm{~g}$ biomass ( $\mathrm{g}$ ethanol $)^{-1}$ between dilution rates of $0 \cdot 10$ and $0 \cdot 19 \mathrm{~h}^{-1}$. The $\mu_{\max }$ was $0.21 \mathrm{~h}^{-1}$, as also reported by Postma et al. (1989b). The $\mathrm{qO}_{2}$ in cultures without benzoate increased linearly, from $6.8 \pm 0.5$ at $D=$ $0 \cdot 10 \mathrm{~h}^{-1}$, to a maximal value of $14 \pm 1 \mathrm{mmol} \mathrm{g}^{-1} \mathrm{~h}^{-1}$ at $D=0 \cdot 19 \mathrm{~h}^{-1}$ (Figure 7). In the presence of benzoate, the highest $\mathrm{qO}_{2}$ that could be obtained was 21.5 at $D=0.10 \mathrm{~h}^{-1}$ and $19 \pm 1 \mathrm{mmol} \mathrm{g}^{-1} \mathrm{~h}^{-1}$ at $D=0 \cdot 19 \mathrm{~h}^{-1}$. When the results are plotted in terms of ethanol fluxes it is remarkable that the observed ethanol flux in the presence of benzoate is similar for all dilution rates and that it is higher than the maximal ethanol flux achieved without benzoate (Figure 8).

The enzymes measured previously in glucoselimited cultures were also assayed in ethanol-limited cultures grown in the presence or absence of benzoate. The results (Table 2) differ considerably from those observed for glucose-limited cultures. In the latter, a significant decrease in, for example, catalase and acetaldehyde dehydrogenase levels was observed. In ethanol-limited cultures, catalase, for instance, was not affected by the presence of benzoate, and an increase was observed in the level of acetaldehyde 


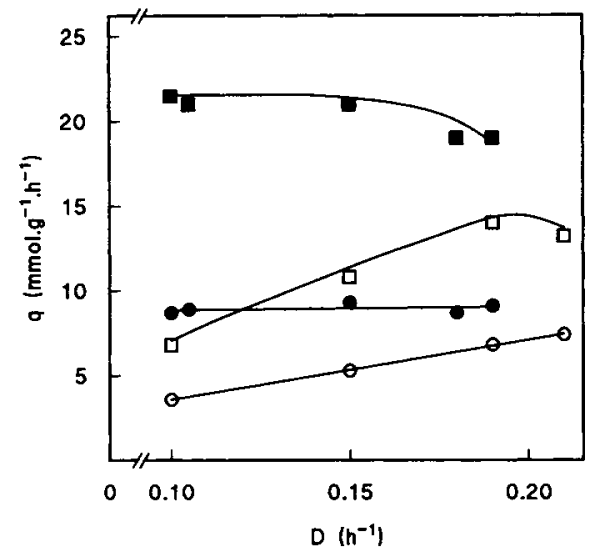

Figure 8. Critical respiratory capacity $(\square)$ and ethanol flux (O) in the presence of benzoate, and $\mathrm{qO}_{2}(\square)$ and ethanol flux (O) in the absence of benzoate during ethanol-limited growth of S. cerevisiae CBS 8066.

dehydrogenase(s). Hexokinase activity was only a third of that in glucose-limited chemostat cultures. From these results it can be concluded that, in ethanol-limited cultures, repression of the assayed enzymes does not occur. This is in sharp contrast to the results with glucose-limited cultures (Figure $6 \mathrm{~A}-\mathrm{C})$.

\section{Mitochondrial volume in $\mathrm{S}$. cerevisiae}

The in-situ respiration rate $\left(\mathrm{qO}_{2}\right)$ and the maximum instantaneous respiration capacity $\left(\mathrm{qO}_{2}{ }^{\max }\right)$, measured in cultures grown in the absence of benzoate, depends on the carbon source. Both these values are higher in ethanol-limited cultures than in glucose-limited cultures grown at the same dilution rates (Table 3). Measurement of the mitochondrial volume indicated that ethanol-limited cells had a higher mitochondrial volume than glucose-limited cells. Growth of glucose- and ethanol-limited cultures in the presence of benzoate resulted in an increase of the mitochondrial volume up to a maximum of $26 \%$ of the cell volume (Table 3 ). The large mitochondrial volume of cells grown in the presence of benzoate is readily apparent from electron micrographs (not shown).

\section{Effect of benzoate on glucose-limited cultures of Crabtree-negative yeasts}

The in-situ $\mathrm{qO}_{2}$ for Crabtree-negative yeasts, grown in carbon-limited chemostat cultures without benzoate, usually increases linearly with the dilution rate (for examples see Alexander and Jeffries, 1990; Barford, 1990). For C. utilis, for example, the in-situ specific oxygen uptake rate in glucose-limited cultures in the absence of benzoate increased from $2.5 \pm$ 0.2 to $14 \pm 1 \mathrm{mmol} \mathrm{O}_{2} \mathrm{~g}^{-1} \mathrm{~h}^{-1}$ when the dilution rate was increased from $0 \cdot 10$ to $0.55 \mathrm{~h}^{-1}$ (Figure 9). At high dilution rates considerable accumulation of pyruvate occurred, with a maximal concentration of $2.5 \mathrm{~mm}$ at $D=0.55 \mathrm{~h}^{-1}$ (Figure 9).

Addition of benzoate to the medium reservoir of glucose-limited chemostat cultures of C.utilis, and of other Crabtree-negative yeasts such as $K$. marxianus and $H$.polymorpha, resulted in a similar behaviour as observed with $S$. cerevisiae: a decrease in yield and an increase in $\mathrm{qO}_{2}$. Surprisingly, alcoholic fermentation also occurred for all three species when the critical respiratory capacity was reached. The critical respiratory capacity of $C$. utilis increased from $9.0 \pm 1.0 \mathrm{mmol} \mathrm{g}^{-1} \mathrm{~h}^{-1}$ at $D=0.10 \mathrm{~h}^{-1}$ to $14.1 \pm$ $1.0 \mathrm{mmol} \mathrm{g}^{-1} \mathrm{~h}^{-1}$ at $D=0.55 \mathrm{~h}^{-1}$ (Figure 9). Growth in the presence of benzoate at this dilution rate did not result in an increase in $\mathrm{qO}_{2}$ but in a gradual wash-out.

The pattern of $\mathrm{qO}_{2}{ }^{\text {crit }}$ as a function of the dilution rate as observed with C. utilis (Figure 9) was rather different from that of $S$. cerevisiae (Figure 4). In $C$. utilis the $\mathrm{qO}_{2}^{\text {crit }}$ increased with increasing dilution rate and became equal to the in-situ $\mathrm{qO}_{2}$, without benzoate, at $\mu_{\max }$ (Figure 9). In $S$. cerevisiae, however, the $\mathrm{qO}_{2}{ }^{\text {crt }}$ declined with the dilution rate and became equal to the in-situ $\mathrm{qO}_{2}$ at a dilution rate below $\mu_{\max }$ (Figure 4).

The $\mathrm{qO}_{2}{ }_{2}^{\text {crit }}$ may be regarded as a reflection of the highest attainable level of a rate-limiting key respiratory enzyme. The maximum level of this hypothetical enzyme, in turn, will depend on its maximum rate of synthesis (assuming that turnover is low). In order to compare the regulation of respiratory activity of $S$. cerevisiae and C. utilis, it therefore is relevant to compare the product of the critical oxygen consumption rate and the dilution rate. In chemostat mathematics this product is known as productivity, in this case of (a) critical component(s) of the respiratory machinery. The results shown in Figure 10 accentuate the differences in the regulation of the synthesis of the respiratory machinery in S. cerevisiae and $C$. utilis as reflected in Figures 4 and 9.

For $K$. marxianus and H.polymorpha, the critical respiratory capacity was only determined at $D=$ $0 \cdot 10 \mathrm{~h}^{-1}$. Values of 12.0 for $K$. marxianus, and $11.5 \mathrm{mmol} \mathrm{g} \mathrm{g}^{-1} \mathrm{~h}^{-1}$ for H.polymorpha were observed (Table 4), much lower than the value of $19.5 \mathrm{mmol} \mathrm{g}^{-1} \mathrm{~h}^{-1}$ for S. cerevisiae (Table 4). 
Table 2. Specific enzyme activities ( $\left.\mathrm{U} \mathrm{mg}_{\text {protein }}{ }^{-1}\right)$ in ethanol-limited chemostat cultures of S. cerevisiae CBS 8066, in the absence of benzoate and in the presence of $7.8 \mathrm{~mm}$ residual benzoate, respectively, in relation to the specific ethanol and oxygen consumption rates $\left(\mathrm{q}, \mathrm{mmol} \mathrm{g}^{-1} \mathrm{~h}^{-1}\right)$

\begin{tabular}{|c|c|c|c|}
\hline \multirow[b]{2}{*}{ Dilution rate $\left(\mathrm{h}^{-1}\right)$} & \multicolumn{2}{|c|}{ No benzoate } & \multirow{2}{*}{$\frac{\text { With benzoate }}{0 \cdot 10}$} \\
\hline & $0 \cdot 10$ & $0 \cdot 19$ & \\
\hline \multicolumn{4}{|c|}{ Specific consumption rates } \\
\hline q Ethanol & $3 \cdot 6$ & $6 \cdot 8$ & $8 \cdot 3$ \\
\hline $\mathrm{qO}_{2}$ & $6 \cdot 8$ & $14 \cdot 0$ & $20 \cdot 0$ \\
\hline \multicolumn{4}{|l|}{ Enzyme activities } \\
\hline \multicolumn{4}{|c|}{ Acetaldehyde dehydrogenase } \\
\hline $\mathrm{NAD}^{+}$ & 0.48 & 0.92 & $1 \cdot 07$ \\
\hline $\mathrm{NADP}^{+}$ & $0 \cdot 17$ & $0 \cdot 23$ & $0 \cdot 38$ \\
\hline Acetyl-CoA synthetase & 0.46 & 0.37 & $0 \cdot 28$ \\
\hline \multicolumn{4}{|l|}{ Alcohol dehydrogenase } \\
\hline Ethanol & $9 \cdot 0$ & nd & $6 \cdot 8$ \\
\hline Pentanol & $2 \cdot 9$ & nd & $3 \cdot 1$ \\
\hline Catalase & $3 \cdot 0$ & $3 \cdot 3$ & $3 \cdot 6$ \\
\hline Citrate synthase & $1 \cdot 10$ & $1 \cdot 22$ & $1 \cdot 27$ \\
\hline Cytochrome $c$ oxidase & $0 \cdot 24$ & $0 \cdot 21$ & $0 \cdot 26$ \\
\hline Hexokinase & 0.56 & nd & 0.66 \\
\hline NADH dehydrogenase & 1.00 & $1 \cdot 22$ & $1 \cdot 21$ \\
\hline
\end{tabular}

nd: Not determined.

Table 3. In-situ respiration rate $\left(\mathrm{qO}_{2}\right)$, instantaneous $\mathrm{qO}_{2}$ of washed cells in the presence of excess glucose $\left(\mathrm{qO}_{2}^{\max }\right)$, and mitochondrial volume (as percentage of total cell volume) in S. cerevisiae CBS 8066 grown in glucose- or ethanol-limited cultures in the absence or presence of benzoate. The dilution rate was $0.10 \mathrm{~h}^{-1}$

\begin{tabular}{lcccc}
\hline Carbon source & Glucose & \multicolumn{2}{c}{ Ethanol } \\
\hline Benzoate $(\mathrm{mm})$ & 0 & 9 & 0 & $7 \cdot 8$ \\
$\mathrm{qO}_{2}\left(\mathrm{mmol} \mathrm{g}^{-1} \mathrm{~h}^{-1}\right)$ & $2 \cdot 5$ & 17 & $6 \cdot 6$ & 20 \\
$\mathrm{qO}_{2}^{\max }\left(\mathrm{mmol} \mathrm{g}^{-1} \mathrm{~h}^{-1}\right)$ & $4 \cdot 5$ & nd & $9 \cdot 0$ & nd \\
Mitochondrial volume $(\%)$ & 13 & 22 & 19 & 26 \\
\hline
\end{tabular}

nd: Not determined.

The highest fermentation rate observed with Crabtree-negative yeasts in the presence of benzoate at low dilution rates was considerably lower than that for $S$. cerevisiae. In order to establish whether the enzyme patterns as observed for $S$. cerevisiae upon addition of benzoate (Figure 6A-C) also occur in a Crabtree-negative species, the same enzymes were measured for $K$. marxianus at a dilution rate of $0 \cdot 10 \mathrm{~h}^{-1}$. This was done for two situations: firstly without benzoate and secondly at the critical respiration rate induced by benzoate. The enzyme patterns were similar to those observed with $S$. cerevisiae, with a large decline in all the glucoserepressible enzymes. In contrast to $S$. cerevisiae, $K$. marxianus also showed a decrease in cytochrome $c$ oxidase (Table 5).

\section{Regulation of alcoholic fermentation in yeasts}

The Crabtree-negative yeasts investigated in this study are facultatively fermentative (Barnett et al., 


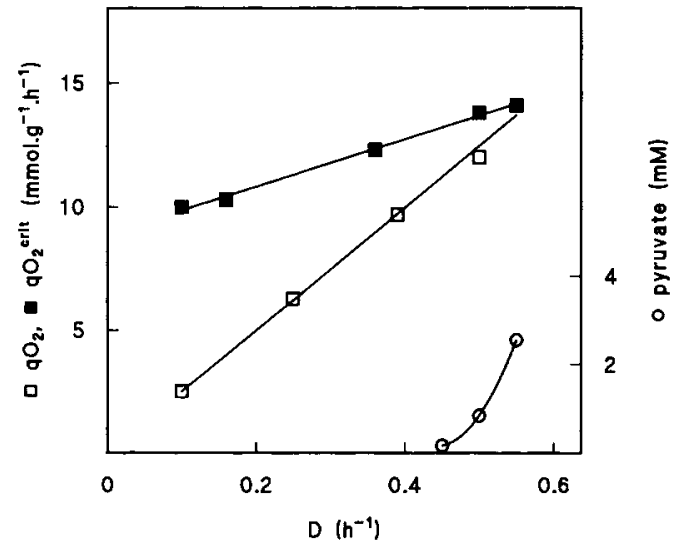

Figure 9. Critical respiratory capacity in the presence of benzoate ( $\mathrm{e}$ ), and $\mathrm{qO}_{2}(\square)$ and pyruvate concentration $(O)$ in the absence of benzoate during glucose-limited chemostat growth of C. utilus CBS 621 .

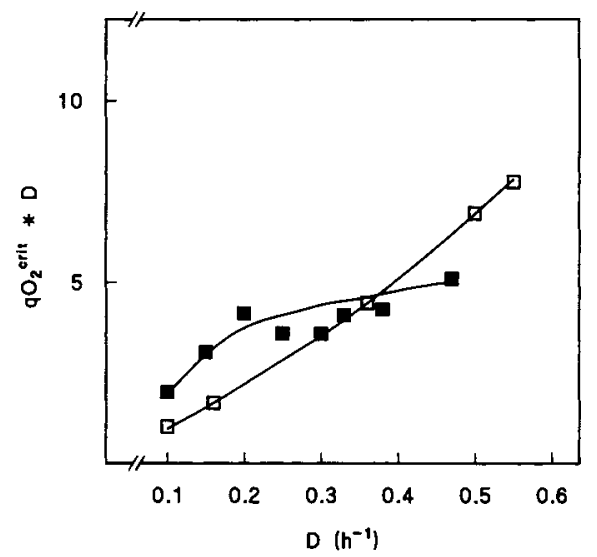

Figure 10. Calculated maximal synthesis rate of the respiratory machinery (critical $\mathrm{qO}_{2}{ }^{*} D$ ) as a function of the dilution rate in glucose-limited cultures of $S$. cerevisiae CBS 8066 (D) and C. utilis CBS $621(\square)$.

1990). When grown under oxygen limitation, for example in shake-flask cultures, these yeasts exhibit alcoholic fermentation at a rate comparable to that obtained with $S$. cerevisiae (Van Dijken and Scheffers, 1986). However, the rates of aerobic alcoholic fermentation that could be provoked in Crabtree-negative yeasts by high benzoate concentrations were far lower than those observed with $S$. cerevisiae. It was therefore decided to compare the benzoate-triggered aerobic alcohol fermentation with an oxygen-limited situation, particularly with respect to enzyme levels. To this end, $S$. cerevisiae and the Crabtree-negative yeasts $C$. utilis, $H$. polymorpha and $K$. marxianus were grown under oxygen limitation at $D=0 \cdot 1 \mathrm{~h}^{-1}$, as described in Materials and Methods. For all yeasts, steady states were obtained that were characterized by a low biomass yield and the presence of considerable quantities of ethanol and glycerol (Table 6) and, to a much lesser extent, pyruvate and acetate. The actual oxygen uptake rate could not be accurately measured under these conditions, but assay of washed cell samples showed that the cells had retained a low respiration capacity (Table 6). From Table 7 it can be seen that oxygen-limited conditions led to ethanol production rates considerably higher than those observed in the aerobic cultures with benzoate. Furthermore, the PDC level was higher under oxygen-limited conditions. In contrast, ADH levels were not positively correlated with the fermentation rate. Interpretation of ADH assays is complicated, however, by the fact that several isoenzymes of ADH may occur at the same time, as mentioned above. In conditions of a low glucose flux, i.e. in aerobic cultures grown in the absence of benzoate, a high ADH activity was found. In cultures with an increased glucose flux, repression of assimilatory and mitochondrial ADHs occurred (Table 7).

\section{DISCUSSION}

\section{Metabolic effects of weak acids}

The effect of addition of various acids to the medium reservoir of anaerobic glucose-limited cultures of S. cerevisiae CBS 8066 and $\mathrm{H} 1022$ has been studied by Verduyn et al. (1990a,b). Addition of weak acids, including acetate, propionate and butyrate, resulted in a decreased cell yield and an increased ethanol formation. The uncoupling effect of the weak acids appears to be directly related to their liposolubility. A higher solubility will lead to a higher diffusion rate and hence to an increase in the amount of ATP required per time unit to compensate for the influx of the acid (Warth, 1988, 1989; Verduyn et al., 1990a,b). Furthermore, the extent of uncoupling was directly proportional to the residual concentration of acid in the fermenter (Verduyn et al., 1990b). The extent to which the acids affected the bioenergetics of growth could be quantified in terms of loss of ATP per amount of residual acid (Verduyn et al., 1990a,b). Assuming that the P/Oratio did not change as a result of the presence of benzoic acid, it could be calculated that the amount of ATP lost per amount of acid added was similar in anaerobic and aerobic cultures (Verduyn, 1992). This suggests that the uncoupling effect of acids 
Table 4. In-situ $\mathrm{qO}_{2}$ in glucose-limited chemostat cultures of various yeasts in the absence of benzoate, and instantaneous maximum $\mathrm{qO}_{2}\left(\mathrm{qO}_{2}{ }^{\max }\right)$ in washed-cell samples from these cultures, and critical $\mathrm{qO}_{2}\left(\mathrm{qO}_{2}^{\text {crit }}\right)$ in the presence of benzoate. The dilution rate was $0 \cdot 10 \mathrm{~h}^{-1}$

\begin{tabular}{|c|c|c|c|}
\hline \multirow[b]{2}{*}{ Organism } & \multicolumn{2}{|c|}{ No benzoate } & \multirow{2}{*}{$\frac{\text { With benzoate }}{\mathrm{qO}_{2}^{\text {crit }}}$} \\
\hline & $\mathrm{qO}_{2}$ & $\mathrm{qO}_{2}^{\max }$ & \\
\hline C. utilis & $2 \cdot 5$ & $4 \cdot 9$ & $9 \cdot 0$ \\
\hline K. marxianus & $3 \cdot 1$ & $7 \cdot 6$ & $12 \cdot 5$ \\
\hline H. polymorpha & $3 \cdot 3$ & nd & $11 \cdot 5$ \\
\hline S. cerevisiae & $2 \cdot 5$ & $4 \cdot 5$ & $19 \cdot 5$ \\
\hline
\end{tabular}

nd: Not determined.

Table 5. Specific enzyme activities (U mg protein ${ }^{-1}$ ) in glucose-limited chemostat cultures of $K$. marxianus CBS 6556 grown in the absence of benzoate, or in the presence of an amount of benzoate that gave rise to the critical oxygen uptake rate. The dilution rate was $0 \cdot 10 \mathrm{~h}^{-1}$

\begin{tabular}{lcc}
\hline & No benzoate & With benzoate \\
\hline Acetaldehyde dehydrogenase & & \\
$\quad$ NAD $^{+}$ & 0.63 & 0.06 \\
$\quad$ NDP $^{+}$ & 0.13 & 0.03 \\
Acetyl-CoA synthetase & 0.29 & 0.03 \\
Alcohol dehydrogenase & & \\
$\quad$ Ethanol & $2 \cdot 10$ & 0.21 \\
$\quad$ Pentanol & 3.30 & 0.18 \\
Catalase & 13.70 & 4.60 \\
Citrate synthase & 0.35 & 2.30 \\
Cytochrome $c$ oxidase & 0.57 & 0.14 \\
Hexokinase & nd & 2.30 \\
NADH dehydrogenase & 0.94 & 0.62 \\
Pyruvate decarboxylase & 0.05 & 0.04 \\
\hline
\end{tabular}

nd: Not determined.

Table 6. Substrate consumption and product formation during oxygen-limited growth of C. utilis CBS 621, K. marxianus CBS 6556 and S. cerevisiae CBS 8066 in glucose-limited chemostat cultures. The dilution rate was $0 \cdot 10 \mathrm{~h}^{-1}$

\begin{tabular}{lccc}
\hline Organism & C.utilis & K. marxianus & S. cerevisiae \\
\hline Yield $\left(\mathrm{g} \mathrm{g}^{-1}\right)$ & $0 \cdot 11$ & $0 \cdot 10$ & $0 \cdot 13$ \\
q Glucose (mmol g & & & \\
Ethanol $(\mathrm{mM})$ & $5 \cdot 1$ & $5 \cdot 3$ & $4 \cdot 3$ \\
Glycerol (mM) & 90 & 79 & 86 \\
Pyruvate (mM) & $6 \cdot 9$ & $6 \cdot 4$ & $6 \cdot 4$ \\
Acetate (mM) & $0 \cdot 56$ & $0 \cdot 15$ & $0 \cdot 08$ \\
& $0 \cdot 58$ & $1 \cdot 1$ & $0 \cdot 70$ \\
\hline
\end{tabular}


Table 7. Specific rates of glucose consumption and ethanol production $\left(\mathrm{mmol} \mathrm{g}^{-1} \mathrm{~h}^{-1}\right)$, and specific activities ( $\mathrm{U} \mathrm{mg}$ protein ${ }^{-1}$ ) of pyruvate decarboxylase (PDC) and alcohol dehydrogenases (ADH) during aerobic growth in the absence and presence of benzoate, and during oxygen-limited growth (without benzoate) in glucose-limited cultures of C. utilis CBS 621, $K$. marxianus CBS 6556 and $S$. cerevisiae CBS 8066 . The dilution rate was $0 \cdot 10 \mathrm{~h}^{-1}$

\begin{tabular}{|c|c|c|c|}
\hline \multirow{2}{*}{$\begin{array}{l}\text { Cultivation } \\
\text { condition }\end{array}$} & \multicolumn{2}{|c|}{ Aerobic } & \multirow{2}{*}{$\begin{array}{l}\text { Oxygen-limited } \\
\text { (no benzoate) }\end{array}$} \\
\hline & No benzoate & With benzoate & \\
\hline \multicolumn{4}{|l|}{ C. utilis } \\
\hline q Glucose & $1 \cdot 1$ & $3 \cdot 2$ & $5 \cdot 1$ \\
\hline q Ethanol & 0 & 1.9 & $8 \cdot 0$ \\
\hline PDC & 0.08 & $0 \cdot 14$ & $0 \cdot 56$ \\
\hline $\mathrm{ADH}$ & $4 \cdot 80$ & $3 \cdot 40$ & nd \\
\hline \multicolumn{4}{|l|}{ K. marxianus } \\
\hline q Glucose & $1 \cdot 2$ & $4 \cdot 3$ & $5 \cdot 3$ \\
\hline q Ethanol & 0 & $3 \cdot 3$ & $7 \cdot 5$ \\
\hline PDC & 0.05 & $0 \cdot 15$ & $0 \cdot 35$ \\
\hline $\mathrm{ADH}$ & $2 \cdot 10$ & $1 \cdot 3$ & $1 \cdot 5$ \\
\hline \multicolumn{4}{|l|}{ S. cerevisiae } \\
\hline q Glucose & $1 \cdot 1$ & $9 \cdot 3$ & $4 \cdot 3$ \\
\hline q Ethanol & 0 & $11 \cdot 3$ & $6 \cdot 8$ \\
\hline PDC & 0.61 & 0.86 & 0.92 \\
\hline $\mathrm{ADH}$ & $8 \cdot 00$ & 1.90 & nd \\
\hline
\end{tabular}

nd: Not determined.

mainly occurs at the level of the plasma membrane (Figure 1; Verduyn, 1992).

We chose benzoic acid as a model acid for studies under aerobic conditions, as it cannot be metabolized by the yeasts used in this study. Benzoate also has some practical interest as it is commonly used as a food preservative (Jay, 1978; Lueck 1980). Literature data indicate that the action of benzoate is probably more complex than a simple combination of influx of the undissociated acid by diffusion and subsequent proton extrusion via the plasma membrane ATPase. It has been suggested (Warth, 1977, 1988) that yeasts can induce an active (energydependent) transport system for the removal of the benzoate anion (and some other medium-length weak acid anions, including sorbate) by an as yet unresolved mechanism. This would then impose an additional energy drain on the organism.

Regulation of respiration in S. cerevisiae during glucose-limited growth

In cultures without benzoate, the $\mathrm{qO}_{2}$ of Saccharomyces strains increases to a maximum with increasing dilution rates and then becomes constant
(Rieger et al., 1983; Barford, 1990). In order to describe the phenomenon of a constant respiration rate at higher dilution rates, terms such as 'saturated' respiration (Barford, 1981); 'bottlenecks in respiration' (Sonnleitner and Käppeli, 1986) and 'respiration-limited' (e.g. Alexander and Jeffries, 1990) have been used. However, the bottleneck(s) in respiration has (have) not been identified. Barford (1990) has suggested that the drain of mitochondrial intermediates for anabolism limits the amount of intermediates available for respiration. This would be caused by a limiting supply rate of precursors for these intermediates from the cytosol to the mitochondria. However, if this was the case, this still implies that the total transport rate of these intermediates must increase with increasing $D$ to maintain a constant $\mathrm{qO}_{2}$.

We expected that when $\mathrm{qO}_{2}$ reaches its maximum in the presence of benzoate, i.e. reaches the critical respiration capacity, it would become constant and additional energy generation might still occur via alcoholic fermentation. However, once fermentation set in, a significant decrease in $\mathrm{qO}_{2}$ was observed (Figure 2). Apparently a strong repression 
of respiration occurred. The glucose flux in steady state at the maximal benzoate concentration which did not provoke alcoholic fermentation was $3.9 \mathrm{mmol} \mathrm{g}^{-1} \mathrm{~h}^{-1}$ (Figure 2). In cultures without benzoate, $\mathrm{qO}_{2}$ became constant and fermentation started above $D=0.38 \mathrm{~h}^{-1}$ (Postma et al., 1989a), at a $q_{\text {glucose }}$ of $4 \cdot 5$. These data suggest that glucose flux determines the critical respiration capacity that can be reached. This infers that the concentration of the intracellular metabolite(s) responsible for glucose repression, which have not been identified so far (Gancedo, 1987), is similar at a given glucose flux, independent of the dilution rate.

The critical respiratory capacity of $S$. cerevisiae CBS 8066 was not constant over the entire range of growth rates, but exhibited a maximum between $D=0.10$ and $0.20 \mathrm{~h}^{-1}$ (Figure 4). The maximum value of $20-21.5 \mathrm{mmol} \mathrm{O}_{2} \mathrm{~g}^{-1} \mathrm{~h}^{-1}$ observed here is much higher than values previously reported in the literature for the maximal respiration rate in $S$. cerevisiae. For instance, values of 8 and $12 \mathrm{mmol}$ $\mathrm{O}_{2} \mathrm{~g}^{-1} \mathrm{~h}^{-1}$ were found for $S$. cerevisiae $\mathrm{H} 1022$ (Rieger et al., 1983) and strain UNSW 703100 (Barford, 1981), respectively. The net synthesis rate of critical respiratory components can be calculated by multiplying the critical respiratory capacity by the dilution rate. For $S$. cerevisiae, the relation between dilution rate and synthesis rate follows approximately a saturation curve (Figure 10). At dilution rates above $0.2 \mathrm{~h}^{-1}$ the synthesis rate was already sub-maximal, and could not be increased further. Therefore, a high critical respiration capacity cannot be maintained at higher dilution rates, as this would require a continuous increase in the synthesis rate of critical respiratory components with the growth rate. In this respect, in Crabtree-negative yeasts such as $C$. utilis, the regulation of respiration seems to be different. As mentioned in the introduction, it is generally assumed that the respiration capacity of Crabtree-negative species is considerably higher than that of, for instance, $S$. cerevisiae (Alexander and Jeffries, 1990; Barford, 1990). This observation is based on the analysis of $\mathrm{qO}_{2}$ at dilution rates close to $\mu_{\max }$. The higher $\mathrm{qO}_{2}$ is taken to explain the absence of the Crabtree effect as these yeasts can generate sufficient energy for growth from respiration alone. Therefore terms like respiration-sufficient and respiration-limited are sometimes used with respect to Crabtree-negative and -positive species, respectively (e.g. Alexander and Jeffries, 1990).

Quite unexpectedly, a comparison of the critical respiratory capacities provoked by benzoic acid shows that -at low dilution rates - the respiratory capacity of $S$. cerevisiae is significantly higher than that of $C$. utilis and other Crabtree-negative yeasts (Table 4). However, at higher dilution rates the apparent synthesis rate of the respiratory system of C. utilis did not level off as in S. cerevisiae, but rather increased almost linearly with the dilution rate (Figure 9). Hence it can be concluded that the respiratory capacity of $S$. cerevisiae is not intrinsically lower than that of Crabtree-negative yeasts: this is only the case at higher dilution rates.

It is commonly assumed that repression of respiration is associated with growth on sugars, which are metabolized via pyruvate (Gancedo and Serrano, 1989). The critical oxygen uptake rates observed in ethanol-limited cultures grown at $D=0 \cdot 10 \mathrm{~h}^{-1}$ in the presence of benzoate were slightly $(10 \%)$ higher than those in glucose-limited cultures, both in the absence and in the presence of benzoate (compare Figures 2 and 7). However, this difference is too small to decide whether during ethanol and glucose catabolism, the respiratory capacity is limited by the same step, for instance in the TCA cycle, respiratory chain or the mitochondrial ATP/ADP-translocation, or whether glucose catabolism is limited by a different step, for instance in transport or oxidation of pyruvate.

\section{Effect of benzoate pulses on the physiology of}

S. cerevisiae

In the course of our studies on the effects of benzoate in yeast physiology, it was observed that gradual adaptation of the yeasts to the presence of benzoate took place: the $\mathrm{qO}_{2}{ }^{\text {crit }}$ could only be reached via gradual adaptation of cultures to increasing reservoir benzoate concentrations. It was therefore of interest to investigate the effects of a sudden exposure to high benzoate concentrations via a direct addition to the culture. Such a direct pulse resulted in phenomena completely different from those observed upon stepwise increases of the reservoir concentration. Under the latter condition, growth in the presence of $10 \mathrm{~mm}$-benzoate resulted in a completely respiratory metabolism with a very high $\mathrm{qO}_{2}$ (Figure 2). However, a direct pulse of benzoate resulted in a severe reduction of in-situ $\mathrm{qO}_{2}$. This $\mathrm{qO}_{2}$ is probably due to oxidation of reducing equivalents formed in the production of acetate, which accumulated up to $25 \mathrm{~mm}$ (Figure 3B). It appears that functioning of the TCA cycle (or supply of its intermediates) is inhibited under these conditions, but that oxidation of reducing equivalents can still take place, at least to some extent. The effect of a pulse-wise addition of benzoate to the 
fermenter on the respiration rate was completely reversible (Figure $3 \mathrm{C}$ ): washed cell suspensions had the same oxygen uptake rate $\left(4-5 \mathrm{mmol} \mathrm{g}^{-1} \mathrm{~h}^{-1}\right.$, Table 3) in the presence of excess glucose as normally observed in cells grown without benzoate at this $D$. A very unusual feature is the fact that virtually no ethanolic fermentation occurred, despite considerable glucose accumulation (Figure 3A). In all other cases we have encountered so far, glucose accumulation resulted in a high specific ethanol production rate. For instance, glucose pulses to $S$. cerevisiae CBS 8066 led to both increased specific oxygen uptake rates and considerable alcoholic fermentation (van Urk et al., 1988). Similar results have been obtained with other Saccharomyces strains (Rieger et al., 1983). The reason for the low ethanol production rate of $S$. cerevisiae, despite significant glucose accumulation, after a pulse of benzoate, remains to be established.

\section{Effect of benzoate on enzyme levels in S. cerevisiae}

It has previously been shown that enzyme levels in glucose-limited $S$. cerevisiae were affected by the glucose flux. With increasing dilution rates, i.e. increasing glucose flux, repression of a number of enzymes was observed (Postma et al., 1989a). Also at a fixed dilution rate, but at different glucose fluxes as a result of growth in the presence of benzoate, a decline in the activity of a number of enzymes was observed (Figure 6A-C). It can be argued that the synthesis of these enzymes is affected by benzoate. In order to establish whether for instance catalase synthesis is influenced by benzoate, levels of this enzyme were assayed in ethanol-limited cultures of $S$. cerevisiae grown without or with $8 \mathrm{~mm}$ residual benzoate. The catalase activities were similar (Table 2). This indicates that catalase is indeed not subject to repression in ethanol-limited cultures and furthermore that its total activity in biomass is not affected by benzoate. The same is true for acetaldehyde dehydrogenases, the activity of which actually increased when the ethanol flux was increased, either by increasing the dilution rate, or by adding benzoate at a fixed $D$ (Table 2). However, it should be kept in mind that in the enzyme assays no benzoate is present and thus the possibility cannot be excluded that benzoate inhibits an enzyme activity in vivo.

The activity of hexokinases, which have no apparent major role in ethanol metabolism, were considerably lower than in glucose-limited cultures. Less clear is the behaviour of ADH(s) and acetylCoA synthetase, which showed some decrease at
$D=0 \cdot 10 \mathrm{~h}^{-1}$ in the presence of benzoate. A decrease in enzyme activities was also observed at a higher dilution rate $\left(0 \cdot 19 \mathrm{~h}^{-1}\right)$ in the absence of benzoate. It is clear that the regulation of enzyme activity during growth on ethanol is quite different from that during growth on glucose, both with and without benzoate.

Some enzymes of the TCA cycle and of the respiratory chain were also assayed. Interestingly, citrate synthase increased three-fold in glucose-limited cultures grown in the presence of benzoate, although glucose repression of this enzyme has been reported in batch cultures (Wales et al., 1980). However, it is still possible that benzoate might bind to this enzyme and that the in-situ activity is reduced, hence a larger amount of enzyme would be required. However, in ethanol-limited cultures, its activity was uniformly high (with and without benzoate addition; Table 2). A similar large increase was also observed for citrate synthase in $K$. marxianus upon addition of benzoate (Table 5). NADH-dehydrogenase activity showed some decline with increasing glucose flux, whereas cytochrome $c$ oxidase activity increased slightly. Hence it can be concluded that, although only a small selection of enzymes have been assayed in this work, the results (Figure 6A-C) suggest that the increased glycolytic and respiratory fluxes in the presence of benzoate must be mainly due to a rise in the concentration of intracellular intermediates. Furthermore, there appears to be no major difference in the enzyme patterns of $S$. cerevisiae and $K$. marxianus (compare Figure $6 \mathrm{~A}-\mathrm{C}$ and Table 5). Not only in glucoselimited cultures, but also in ethanol-limited cultures, levels of intermediates probably are decisive for metabolic fluxes. However, in contrast to growth on glucose, repression of enzymes did not occur during growth on ethanol in the presence of benzoate: the levels of various enzymes were almost independent of the ethanol flux.

\section{Mitochondrial volume in relation to respiration rate}

The large increase of the mitochondrial volume observed upon addition of benzoate to glucoselimited cultures of $S$. cerevisiae (Table 3 ) is unlikely to be solely due to an increase in the amount of mitochondrial protein. Of the mitochondrial enzymes assayed, only citrate synthase increased significantly (Figure 7C). Cells grown on ethanol showed a larger mitochondrial volume than cells grown on glucose in the absence of benzoate, but had a considerably higher in-situ $\mathrm{qO}_{2}$ and instantaneous maximum $\mathrm{qO}_{2}$ (Table 3). The increase in mitochondrial volume possibly serves to increase the area 
available for respiration-linked processes, which might serve to accommodate increased amounts of the electron transport chain or various carriers (e.g. for pyruvate and/or ADP/ATP exchange).

\section{Regulation of alcoholic fermentation}

Our results show that in Crabtree-negative yeasts alcoholic fermentation can be provoked under aerobic conditions which impose a large demand for ATP, as is the case during growth in the presence of benzoate (Tables 6 and 7). However, the observed maximal fermentation rate at low dilution rates, as induced by benzoate, was lower in Crabtree-negative yeasts than in S. cerevisiae (Table 7). This appears to be due to the inability of the Crabtree-negative species to induce higher PDC levels upon transition to partly fermentative conditions (Table 7). It has already been proposed that the level of PDC is rate-limiting for the fermentation (Schmitt and Zimmerman, 1982; Sharma and Tauro, 1986). A good correlation between fermentation rate and PDC level was also observed in glucose-limited chemostat cultures of $S$. cerevisiae 8066 (Postma et al., 1989a). A further important enzyme in the context of fermentative capability is ADH. The activity of ADH was considerably higher than that of PDC. Although ADH activity may be due to several isoenzymes (Lutstorf and Magnet, 1968; Fraenkel, 1982), the reaction from acetaldehyde to ethanol proceeds approximately ten times faster than the oxidation of ethanol (Verduyn et al., 1988). Thus, even if only $25 \%$ of the total ADH activity is due to the fermentative enzyme, it is unlikely that $\mathrm{ADH}$ will become rate-limiting with respect to alcoholic fermentation.

In summary, our results show that the increase in the catabolic flux due to the presence of benzoate is regulated at the level of metabolite concentrations rather than via enhanced enzyme synthesis. Under appropriate cultivation conditions the respiration of $S$. cerevisiae can attain values higher than those observed in Crabtree-negative yeasts. The question why benzoate can trigger such high respiration rates in $S$. cerevisiae only at low growth rates (Figure 4) cannot be answered at present. In our opinion answering this question is a necessity for an understanding of the Crabtree effect.

\section{ACKNOWLEDGEMENTS}

We are indebted to Dr Marten Veenhuis (State University of Groningen) and Wilma Batenburg- van der Vegte of our Department for advice and assistance with electron microscopy. This work was financed by a grant from The Netherlands Organization for Scientific Research (NWO).

\section{REFERENCES}

Alexander, M. A. and Jeffries, T. W. (1990). Respiratory efficiency and metabolite partitioning as regulatory phenomena in yeasts. Enz. Microb. Technol. 12, 2-19.

Barford, J. P. and Hall, R. J. (1979). An examination of the Crabtree effect in Saccharomyces cerevisiae: the role of respiratory adaptation. J. Gen. Microbiol. 114, 267-275.

Barford, J. P. (1981). A mathematical model for the aerobic growth of Saccharomyces cerevisiae with a saturated respiratory capacity. Biotechnol. Bioeng. 13, 1735-1762.

Barford, J. P. (1990). A general model for aerobic yeast growth: continuous culture. Biotechnol. Bioeng. 35, 921-927.

Barnett, J. A., Payne, P. W. and Yarrow, D. (1990). Yeasts, Characterization and Identification. Cambridge University Press, Cambridge.

Bränden, C. I., Jornvall, H., Eklund, H. and Furugren, B. (1975). Alcohol dehydrogenases. In Boyer, P. D. (Ed.), The Enzymes, vol. XIA. Academic Press, New York, pp. 103-190.

Bruinenberg, P. M., van Dijken, J. P., Kuenen, J. G. and Scheffers, W. A. (1985). Critical parameters in the isolation of mitochondria from Candida utilis. J. Gen. Microbiol. 131, 1835-1842.

Fiechter, A., Fuhrmann, G. F. and Käppeli, O. (1981). Regulation of glucose metabolism in growing yeast cells. Adv. Microbial Physiol. 22, 123-183.

Fraenkel, D. G. (1982). Carbohydrate metabolism. In Strathern, J. N., Jones, E. W. and Broach, J. R. (Eds), The Molecular Biology of the Yeast Saccharomyces, Metabolism and Gene Expression. Cold Spring Harbor Laboratories, Cold Spring Harbor, New York, pp. 1-37.

Gancedo, J. M. (1987). Approaches to the study of catabolite repression in yeasts. In Korhola, $M$. and Nevalainen, H. (Eds), Proceedings of the Alko Symposium on Industrial Yeast Genetics. Foundation for Biotechnical and Industrial Fermentation Research, vol. 5, pp. 59-73.

Gancedo, C. and Serrano, R. (1989). Energy-yielding metabolism. In Rose, A. H. and Harrison, J. S. (Eds), The Yeasts, vol. 3. Academic Press, London, pp. 205-259.

Harder, W., Visser, K. and Kuenen, J. G. (1974). Laboratory fermenter with an improved magnetic drive. Lab. Practice 23, 644-645.

Holzer, H. and Goedde, H. W. (1957). Zwei Wege von Pyruvat zu Acetyl-Coenzym $A$ in Hefe. Biochem. $Z$. 329, 175-191. 
Jay, M. J. (1978). In Modern Food Microbiology. D. van Nostrand Comp., New York, Cincinnati, Toronto, London, Melbourne, pp. 163-165.

Käppeli, O. (1986). Regulation of carbon metabolism in Saccharomyces cerevisiae and related yeasts. $A d v$. Microbial Physiol 28, 181-209.

Lueck, E. (1980). In Antimicrobial Food Additives. Springer Verlag, Berlin, Heidelberg, New York, pp. 210-217.

Lutstorf, U. and Magnet, A. (1968). Multiple forms of alcohol dehydrogenase in Saccharomyces cerevisiae. Arch. Biochem. Biophys. 126, 933-944.

Parulekar, S. J., Semones, G. B., Rolf, M. J., Lievense, J. C. and Lim, H. C. (1986). Induction and elimination of oscillations in continuous cultures of Saccharomyces cerevisiae. Biotechnol. Bioeng. 28, 700-710.

Petrik, M., Käppeli, O. and Fiechter, A. (1983). An expanded concept for the glucose effect in the yeast Saccharomyces cerevisiae: involvement of short- and long-term regulation. J. Gen. Microbiol. 129, 43-49.

Pirt, S. J. (1965). The maintenance energy of bacteria in growing cultures. Proc. Royal Soc. London 163B, 224-231.

Postma, E., Scheffers, W. A. and van Dijken, J. P. (1988). Adaptation of the kinetics of glucose transport to environmental conditions in the yeast Candida utilis CBS 621: a continuous-culture study. J. Gen. Microbiol. 134, 1109-1116.

Postma, E., Verduyn, C., Scheffers, W. A. and van Dijken, J. P. (1989a). Enzymic analysis of the Crabtree effect in glucose-limited chemostat cultures of Saccharomyces cerevisiae. Appl. Env. Microbiol. 55, 468-477.

Postma, E., Scheffers, W. A. and van Dijken, J. P. (1989b). Kinetics of growth and glucose transport in glucose-limited chemostat cultures of Saccharomyces cerevisiae CBC 8066. Yeast 5, 159-165.

Ratledge, C. (1991). Yeast physiology-a micro-synopsis. Bioproc. Eng. 6, 195-203.

Rieger, M., Käppeli, O. and Fiechter, A. (1983). The role of limited respiration in the incomplete oxidation of glucose by Saccharomyces cerevisiae. J. Gen. Microbiol. 129, 653-661.

Schmitt, H. D. and Zimmerman, F. K. (1982). Genetic analysis of the pyruvate decarboxylase reaction in yeast glycolysis. J. Bacteriol. 151, 1146-1152.

Sharma, S. and Tauro, P. (1986). Control of ethanol production by yeast: role of pyruvate decarboxylase. Biotechnol. Lett. 8, 735-738.

Sonnleitner, B. and Käppeli, O. (1986). Growth of Saccharomyces cerevisiae is controlled by its limited respiratory capacity: formulation and verification of a hypothesis. Biotechnol. Bioeng. 28, 927-937.

Sonnleitner, B. (1991). Dynamics of yeast metabolism and regulation. Bioproc. Eng. 6, 187-193.

Srere, P. A. (1969). Citrate synthase. Meth. Enzymol. 13, 3-11.

Valle, E. L., Bergillos, L., Gascón, S., Parra, F. and Ramos, S. (1986). Trehalase activation in yeasts is mediated by an internal acidification. Eur. J. Biochem. 154, 247-251.

Van Dijken, J. P. and Scheffers, W. A. (1986). Redox balances in the metabolism of sugars in yeasts. FEMS Microbiol. Rev. 32, 199-224.

Van Urk, H., Mak P. R., Scheffers, W. A. and van Dijken, J. P. (1988). Metabolic responses of Saccharomyces cerevisiae CBS 8066 and Candida utilis CBS 621 upon transition from glucose limitation to glucose excess. Yeast 4, 283-291.

Verduyn, C., Van Dijken, J. P. and Scheffers, W. A. (1984). Continuous measurement of ethanol production by aerobic yeast suspensions with an enzyme electrode. Appl. Microbiol. Biotechnol. 19, 181-185.

Verduyn, C., Breedveld, G. J., Scheffers, W. A. and van Dijken, J. P. (1988). Substrate specificity of alcohol dehydrogenase from the yeasts Hansenula polymorpha CBS 4732 and Candida utilis CBS621. Yeast 4, 143-148.

Verduyn, C., Postma, E., Scheffers, W. A. and van Dijken, J.P. (1990a). Physiology of Saccharomyces cerevisiae in anaerobic glucose-limited chemostat cultures. J. Gen. Microbiol. 136, 395-403.

Verduyn, C., Postma, E., Scheffers, W. A. and van Dijken, J. P. (1990b). Energetics of Saccharomyces cerevisiae in anaerobic glucose-limited chemostat cultures. J. Gen. Microbiol. 136, 405-412.

Verduyn, C. (1992). Energetic aspects of metabolic fluxes in yeasts. PhD. Thesis, Delft University of Technology, The Netherlands, in press.

Visser, W., Scheffers, W. A., Batenburg-van der Vegte, W. H. and van Dijken, J.P. (1990). Oxygen requirements of yeasts. Appl. Env. Microbiol. 56, 3785-3792.

Wales, D. S., Cartledge, T. G. and Lloyd, D. (1980). Effects of glucose repression and anaerobiosis on the activities and subcellular distribution of tricarboxy acid cycle and associated enzymes in Saccharomyces carlsbergensis. J. Gen. Microbiol. 116, 93-98.

Warth, A. D. (1977). Mechanism of resistance of Saccharomyces bailii to benzoic, sorbic and other weak acids used as food preservatives. J. Appl. Bacteriol. 43, 215-230.

Warth, A. D. (1988). Effect of benzoic acid on growth yield of yeasts differing in their resistance to preservatives. Appl. Env. Microbiol. 54, 2091-2095.

Warth, A. D. (1989). Transport of benzoic and propanoic acids by Zygosaccharomyces bailii. J. Gen. Microbiol. 135, 1383-1390.

Weibel, E. R. and Bolender, R. P. (1973). Stereological techniques for electron microscopic morphometry. In Hayat, M. A. (Ed.), Principles and Techniques of Electron Microscopy, vol. 3. London, pp. 237-296.

Woehrer, W. and Roehr, M. (1981). Regulatory aspects of baker's yeast metabolism in aerobic fed-batch cultures. Biotechnol. Bioeng. 23, 567-581. 